\title{
Reliability and Effectiveness of Transmission from Exteroceptive Sensory Neurons to Spiking Local Interneurons in the Locust
}

\author{
Malcolm Burrows \\ Department of Zoology, University of Cambridge, Cambridge CB2 3EJ, England
}

Mechanosensory information from exteroceptive hairs on the legs of a locust is first processed in a segmental ganglion by a midline population of spiking local interneurons for use in adjustments of posture and locomotion. Each interneuron receives excitatory inputs from a characteristic array of these receptors so that the surface of a leg is mapped onto the whole population of interneurons as a series of overlapping receptive fields. The properties of this first synaptic connection, and the contributions of individual afferents forming the receptive fields of the interneurons are examined.

The gain of the excitatory synaptic connection between the hair afferents and the interneurons is often high, so that a single afferent spike can lead directly to a spike in the interneuron. Repetitive spikes in a hair afferent evoke EPSPs in an interneuron that decline in amplitude but that may summate. The first EPSP in any sequence is always the largest. The high frequencies of afferent spikes that are evoked by a normal deflection of a hair saturate the synaptic connection so that the amplitude of depolarization is no greater than to a single spike. The EPSPs from two hairs in a receptive field can summate but lead to no heterosynaptic facilitation. Highfrequency bursts of spikes in one afferent can reduce the postsynaptic effect of another afferent.

The amplitude of the EPSPs and the gain of the synaptic connections differ markedly between the hairs that comprise the receptive field of an interneuron. There are gradients of effectiveness, generally according to the axes of the leg, with one group of adjacent hairs producing the largest-amplitude EPSPs and having the highest gains. Individual hairs may contribute to the receptive field of more than one interneuron, and the gain of these connections may differ.

The complexity of a receptive field is further accentuated by the specificity of connections made by the different physiological types of hair receptors. High-threshold hairs may make synaptic connections with an interneuron, but adjacent low-threshold hairs may not.

This organization of the receptive fields means that the interneurons are sensitive to certain inputs and can reliably pass on a signal from one hair. It also implies that greater weighting is given to inputs from certain regions.

Information from exteroceptors on the legs is essential if an animal is to make appropriate adjustments of its posture and

\footnotetext{
Received Aug. 12, 1991; revised Oct. 29, 1991; accepted Nov. 19, 1991.

This work was supported by NIH Grant NS16058 and in part by a grant from SERC (UK), I thank colleagues at Cambridge and Caltech for their constructive suggestions on the manuscript.

Correspondence should be addressed to Malcolm Burrows, Department of Zoology, University of Cambridge, Downing Street, Cambridge CB2 3EJ, England. Copyright (C) 1992 Society for Neuroscience 0270-6474/92/121477-13\$05.00/0
}

locomotion in response to external influences. The CNS must then be able to localize the position of the stimulus and determine some of its features. In insects, only a few types of exteroceptors are present and are, in comparison to mammals, sparsely distributed, with each innervated by a separate mechanosensory neuron. The strength of a stimulus is therefore signaled by the types of receptor that are excited and by the frequency of their spikes, and the area by the spatial array of receptors that are stimulated. Moreover, in locusts, stimulation of different arrays of receptors leads to distinct reflex movements of a leg (Siegler and Burrows, 1986), indicating that positional information is preserved by the CNS.

Local interneurons appear to be the crucial elements that process these mechanosensory signals and convert them into appropriate motor responses (Burrows and Laurent, 1989). In locusts, the initial step in this processing is largely performed by groups of spiking local interneurons that receive synaptic inputs from hair afferents (Siegler and Burrows, 1983; Nagayama and Burrows, 1990). Members of a midline group then make inhibitory output connections with nonspiking local interneurons (Burrows, 1987b), intersegmental projection interneurons (Laurent, 1987), and motor neurons (Burrows and Siegler, 1982), while members of a second, anteromedial group make excitatory output connections with motor neurons (Nagayama and Burrows, 1990). Each spiking local interneuron is excited by an array of receptors that comprise its receptive field, and the fields of individual interneurons overlap. These interneurons thus provide a precise map of a leg as a series of overlapping receptive fields in which spatial information is preserved. The midline interneurons give a fine representation by virtue of their small fields restricted to one leg, whilc the anteromedial interneurons provide a coarser one in their larger fields, which can include four legs (Nagayama, 1990).

For the sake of simplicity, it has been assumed that the receptors within a receptive field make a uniform contribution to the excitability of a local spiking interneuron. Several observations suggest that this view may be untenable. For example, afferents from certain receptors on a locust leg generate synaptic potentials of different amplitudes in specific midline local spiking interneurons (Burrows and Pflüger, 1986; Laurent and Hustert, 1988); different hair afferents from a proleg of a moth also generate synaptic potentials of different amplitudes in a motor neuron (Weeks and Jacobs, 1987), as do cercal afferents of a cricket (Shepherd et al., 1988), or neck receptors of a locust (Pflüger and Burrows, 1990) on projection interneurons. In only the last example, however, has it been shown that the amplitude of a synaptic potential can be correlated with a differential ability to evoke spikes in a postsynaptic neuron.

This article examines the contribution of individual receptors within the receptive fields of midline spiking local interneurons 
of the locust by posing two questions: first, how effective is a spike in a single hair afferent at evoking a spike in an interneuron, and second, do all the receptors within a receptive field exert the same effect? It is shown that the gain of the synaptic connection from a hair afferent to an interneuron can be high and that individual receptors within a field differ considerably in their effectiveness.

\section{Materials and Methods}

Adult locusts, Schistocerca gregaria (Forskål), of either sex were used from our crowded laboratory cultures. A locust was mounted ventral surface uppermost with the coxa and femur of all the legs restrained, and with the femur of the right hind leg rotated so that its anterior surface was uppermost. This orientation allowed access to most of the trichoid sensilla (hereafter called hairs) on the anterior, ventral, and dorsal surfaces of the femur, tibia, and tarsus of this hind leg. The mesoand metathoracic ganglia were exposed and stabilized on a wax-coated platinum platform. The sheath of the ganglia was treated with a $0.1 \%$ $(w / v)$ solution of protease (Sigma type XIV) for 1-2 min before recording began. The thoracic cavity was perfused throughout an experiment with a constant flow of locust saline at $19-23^{\circ} \mathrm{C}$.

All intracellular recordings were made from the cell bodies of local interneurons belonging to a ventral midline group (Burrows and Siegler, 1984; Siegler and Burrows, 1984). Individuals within this group can be recognized by their receptive field on a hind leg, and by their distinctive morphology. Interneurons were recorded that had receptive fields on all parts of the right hind leg, but the most detailed analysis was restricted to those with fields on the accessible anterior, ventral, or dorsal surfaces of the femur or the tibia. Control experiments defining the fields of other interneurons showed no differences in organization compared to those presented here. The results are based on 46 recordings in 30 locusts. The connections and effects of 316 hair afferents were determined (range for each interneuron in a particular experiment, 2-39 hairs). The interneurons for which data are given fall into five categories, defined by receptive field and morphology, and probably therefore representing identified individuals. To define the receptive fields, and to determine the effects of the hair inputs, it was necessary to maintain stable recordings from these interneurons for $0.5-2 \mathrm{hr}$.

Afferent spikes from hairs on the hind leg were recorded by cutting a hair shaft to leave about one-third of its length and then placing a glass microelectrode, filled with locust saline and with a tip diameter of 80-100 $\mu \mathrm{m}$, over the cut end (Hodgson et al., 1955). The electrode was therefore in contact with the fluid in the hair shaft that bathes the dendrite of the afferent neuron. Spikes of a consistent amplitude, indicating the presence of a single mechanosensory neuron innervating each hair, could be evoked by moving the hair shaft with the electrode or by applying a brief electrical current. Simultaneous recordings from many pairs of adjacent hairs showed that a separate afferent innervates each.

Each connection between a hair afferent and an interneuron was established by (1) moving a hair, whose afferent spikes were monitored, to evoke a minimum of 100 spikes at frequencies below $0.5 \mathrm{~Hz}$; (2) moving a hair abruptly with the recording electrode to evoke a burst of spikes at high frequency; or (3) stimulating a hair electrically with single pulses at $0.5 \mathrm{~Hz}$, or with various patterns of pulses. The synaptic potentials generated by procedures 1 and 3 were signal averaged (on- and off-line analyses of 50 sweeps using Cambridge Electronic Design software and computer interface) and displayed as superimposed sweeps on a digital oscilloscope and an $\mathrm{X}-\mathrm{Y}$ plotter. All recordings were stored on magnetic tape.

Selected interneurons were stained by the intracellular injection of cobalt (Brogan and Pitman, 1981) after physiological characterization. The stain was then intensified with silver (Bacon and Altman, 1977), and the neurons were drawn from whole-mounts of the metathoracic ganglion.

\section{Results}

\section{Receptive fields}

The receptive field of a local interneuron in the metathoracic ganglion is defined by the excitatory connections made with it by the afferents from extero- and proprioceptors, and by the inhibitory connections made by other neurons in the CNS. A field can thus consist of an excitatory region formed by the afferent connections and an inhibitory region formed by the central connections. This article deals only with the excitatory fields of midline spiking local interneurons formed by afferents from hairs on one hind leg. The hairs, whose afferents connect with a particular interneuron, are typically grouped together on a leg, so that, for example, an interneuron can be described as having a receptive field on the ventral femur, or on the dorsal tibia. Each interneuron has a characteristic receptive field and a characteristic morphology (Fig. $1 A, B$ ). Furthermore, individual intcrneurons with the same receptive field and with the same morphology can be recognized from locust to locust.

\section{Connections of the hair afferents}

The afferents from hairs within the receptive field of an interneuron make direct excitatory connections with that interneuron (Siegler and Burrows, 1983; Fig. 1). Each afferent spike is followed consistently and after a constant latency by a depolarizing synaptic potential in the interneuron (Fig. $1 C$ ). The latency of the synaptic potential is correlated with the position of the hair on the leg so that all but $1.2-1.3 \mathrm{msec}$ can be explained by the time taken for conduction of the afferent spike to the metathoracic ganglion. The remaining central delay would be sufficient for only one synapse in the pathway.

The synaptic potentials from some hairs evoke spikes in an interneuron, indicating that they are EPSPs (Fig. $1 D, E$ ). Some hair afferents cvokc spikes in an interneuron that arise from different points of the EPSP (Fig. 1D), suggesting that its peak is just below spike threshold and can exceed it only in combination with other synaptic inputs. Consequently, the spikes in the interneuron arise with a variable latency relative to the afferent spike (Fig. 1D). Other hairs, however, evoke spikes in the interneuron with a constant latency relative to the afferent spikes (Fig. 1E), implying that their EPSPs are of sufficient amplitude to exceed the spike threshold and that the gain of this synaptic connection is higher than the other two.

\section{Properties of the synaptic connection}

A normal movement of a hair is signaled by a burst of many spikes at frequencies as high as $200 \mathrm{~Hz}$. All the hairs are directionally sensitive but are divisible into low- and high-velocity threshold types (Newland, 1991a). Most are phasotonic with a response to a maintained movement that adapts rapidly to zero within a few seconds. If repetitive spikes are evoked in a single hair afferent, then their associated EPSPs start to decrement (Fig. 2). For example, if three stimuli are given at $200 \mathrm{msec}$ intervals, then the second EPSP is only $60 \%$ of the amplitude of the first, even though it arises from the same membrane potential (Fig. 2A). The third EPSP, again arising from the same membrane potential, shows only a small further decrement so that it is $58 \%$ of the amplitude of the first (Fig. $2 \mathrm{~A}$ ). Reducing the intervals between the stimuli still further means that the second and third EPSPs occur on the falling phase of the preceding EPSP (Fig. $2 B-F$ ). These summed EPSPs are usually smaller than the first, and only occasionally when the interval between them is $5 \mathrm{msec}$ or less (Fig. $2 F$ ) is their summed depolarization of larger amplitude than that evoked by a single spike. The duration of the summed depolarization is, however, longer, and this may bc an important parameter in activating the interneuron. Long sequences of stimuli at intervals of 50 msec or less result in a progressive decline of the EPSPs so that even their summed response cannot be detected. 

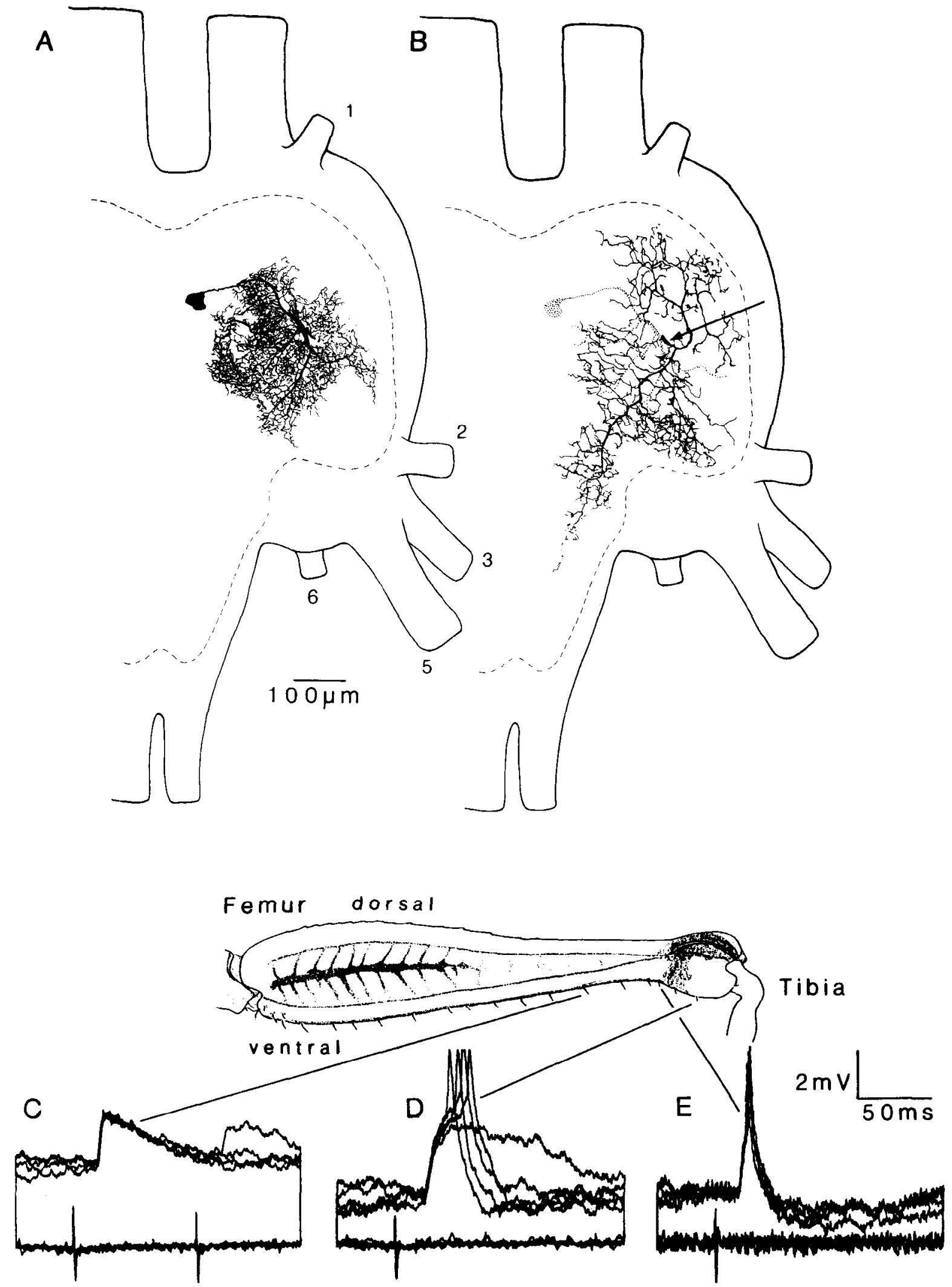

Figure 1. Direct connections between the afferents from hairs on a hind leg and a spiking local interneuron of the midline group. $A$ and $B$, The morphology of the interneuron. The branches are divided into two fields, a ventral field of numerous fine branches $(A)$ and a dorsal field of sparser and more varicose branches $(B)$, linked by a single process (arrow). The right half of the ganglion is shown as viewed dorsally, with anterior at the top. Lateral nerves $1-3,5$, and 6 are numbered, and the broken line indicates the approximate boundary of the neuropil. $C-E$, This interneuron was recorded in two locusts, and the effects of three hairs on the ventral femur were tested. $C$, Superimposed sweeps, triggered by spikes in the single afferent innervating the most proximal of the three hairs, show that an EPSP consistently follows each spike at a constant latency. $D$, A more distal hair again evokes consistent EPSPs in the interneuron, and all but one lead directly to spikes at variable times. $E$, A different hair evokes consistent EPSPs that all evoke spikes at a constant delay. The positions of the hairs are shown in drawings of the anterior surface of a hind femur. 


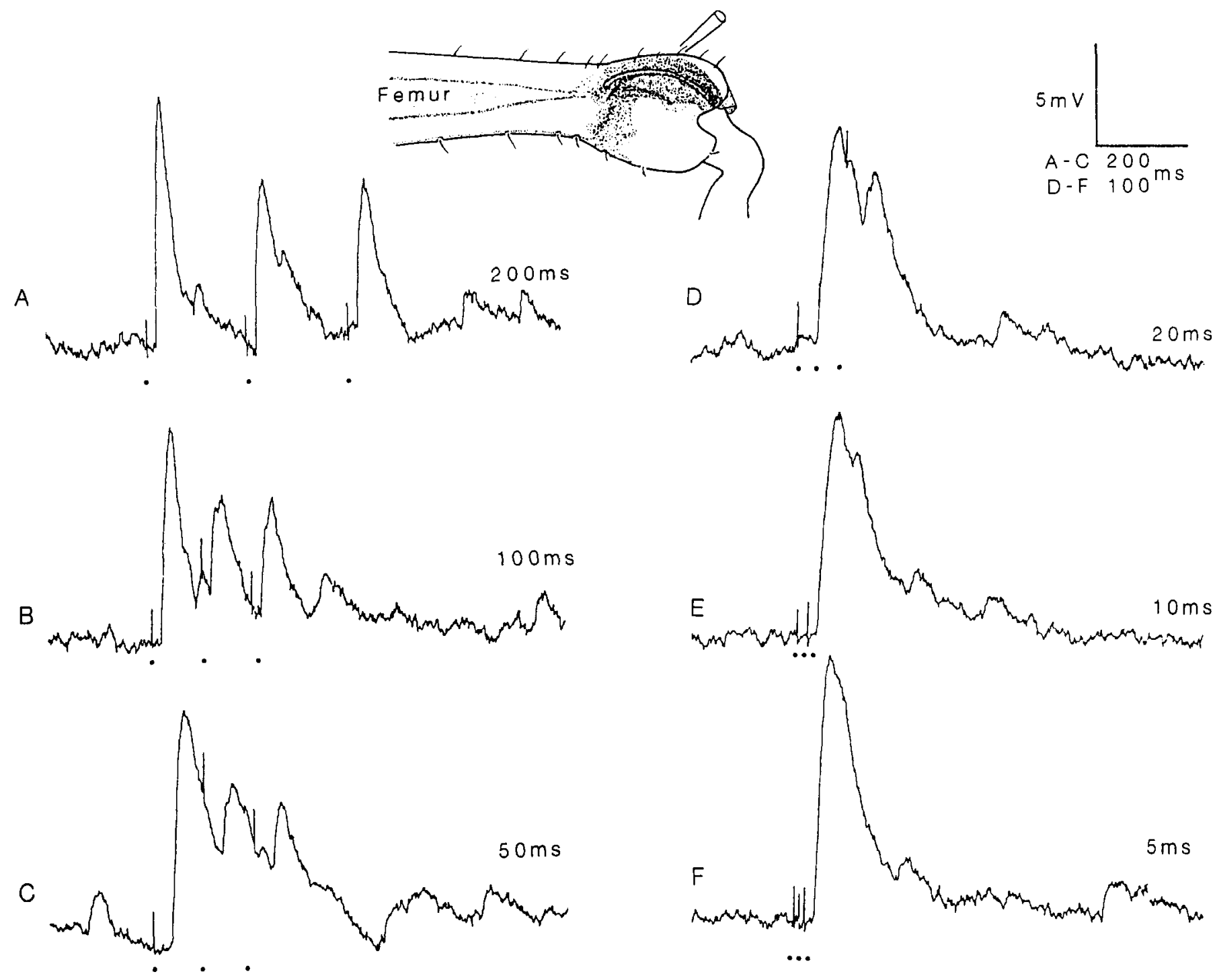

Figure 2. Decrement and summation of the EPSPs in a spiking local interneuron caused by a hair afferent. $A-F$, A hair on the dorsal surface of the distal femur (diagram at the top) was stimulated electrically with three $0.5 \mathrm{msec}$ pulses at intervals ranging from 200 to $5 \mathrm{msec}$. The stimuli are indicated by the electrical artifacts in the intracellular recordings and by the solid circles. Each stimulus evokes a single action potential in the hair afferent, and this in turn evokes a unitary EPSP in the interneuron. The interneuron is held hyperpolarized by a steady current of $0.5 \mathrm{nA}$ to prevent spiking. The amplitude of an EPSP in this and other figures is measured from its initial positive deflection to its peak. Note that the EPSPs are superimposed on a background of synaptic activity that is not linked to the electrical stimuli.

The electrical stimulation experiments suggest that the bursts of spikes generated by hair afferents during a mechanical stimulus should give a depolarization in an interneuron that will be longer but not of greater amplitude than that produced by a single spike. This is confirmed in Figure 3. Small-amplitude movements evoke single spikes and EPSPs of constant amplitude in an interneuron (Fig. $3 A$ ), some of which may lead directly to a spike (Fig. $3 B$ ). A larger deflection of the hair produces a group of spikes and an accompanying sequence of EPSPs that decrement (Fig. 3C). A still larger deflection results in a burst of many spikes at frequencies of $180 \mathrm{~Hz}$ and EPSPs that sum to produce a prolonged depolarization, whose amplitude does not exceed that attained by the first EPSP (Fig. $3 D$ ). These bursts of spikes do not potentiate the EPSP produced by a subsequent afferent spike. A variety of mechanical and electrical stimuli failed to reveal any facilitation of EPSPs by preceding spikes.

\section{Interactions between inputs from hairs within a receptive field}

The spacing of the hairs on the leg is such that mechanical stimuli often excite more than one afferent. These afferents project to the same region of neuropil (Newland, 1991b) and are thus likely to make their synapses close to each other on a postsynaptic interneuron. To determine the extent of interactions between the inputs from nearby hairs, two were stimulated electrically at different intervals (Fig. 4). In the example shown, the more distal hair on the dorsal femur evokes an EPSP with an amplitude that is $25 \%$ greater than that from the proximal hair (Fig. 4A). Reducing the interval between the two afferent spikes leads to the summation of their respective EPSPs (Fig. $4 B-E$ ). At intervals of $5 \mathrm{msec}$, the summed EPSPs exceed the amplitude of the first EPSP by some $34 \%$ and often give rise to a spike (Fig. $4 F$ ). The summation depends not on the order in 

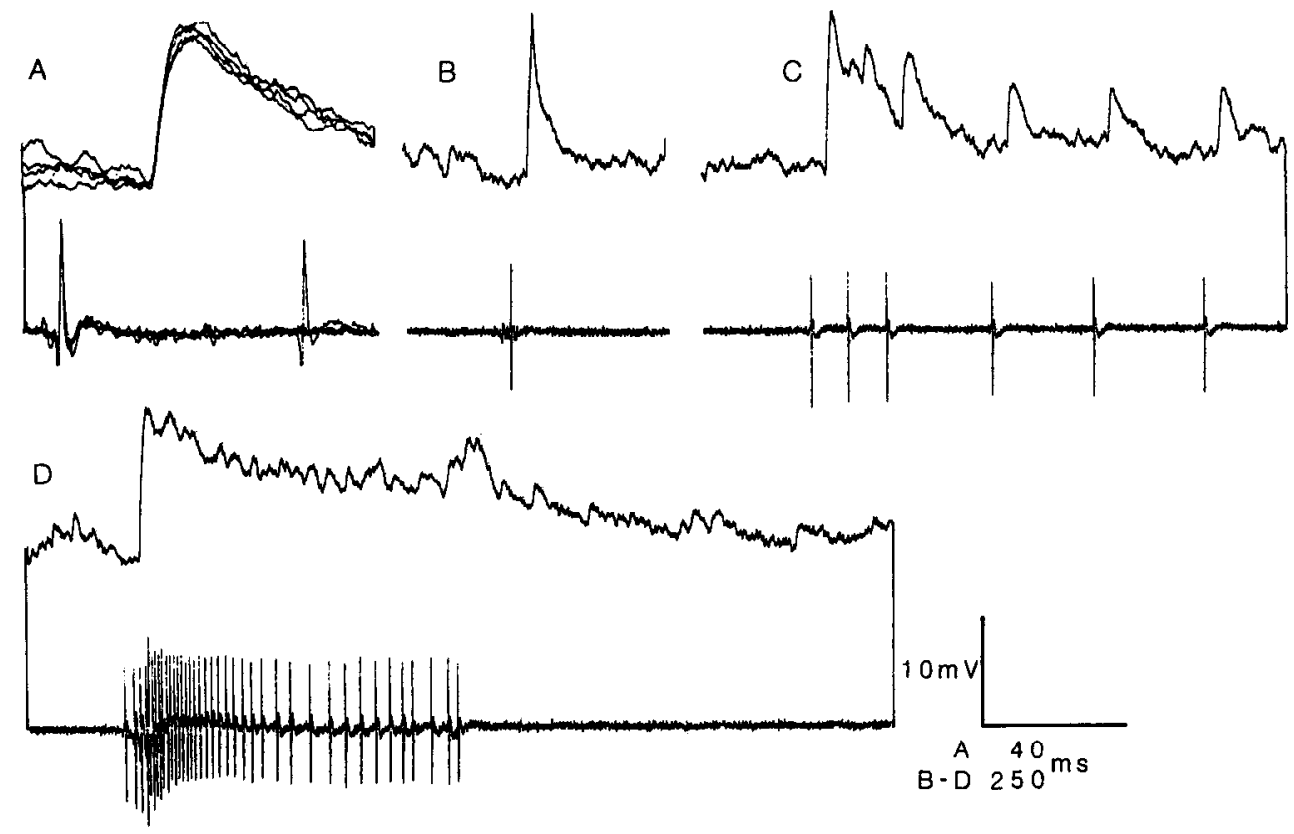

Figure 3. Effects of moving a hair on the dorsal tibia on the evoked depolarization of an interneuron. $A$, Superimposed sweeps of afferent spikes show EPSPs of consistent latency and amplitude. $B$, A single afferent spike evokes an EPSP that is large enough to produce a spike in the interneuron. $C$, In a scquence of six afferent spikes, the first evokes a large EPSP in the interneuron, but subsequent ones give smaller EPSPs. $D$, A rapid movement of the hair evokes a burst of many spikes with some at frequencies of $180 \mathrm{~Hz}$, and the evoked EPSPs sum to produce a prolonged depolarization.

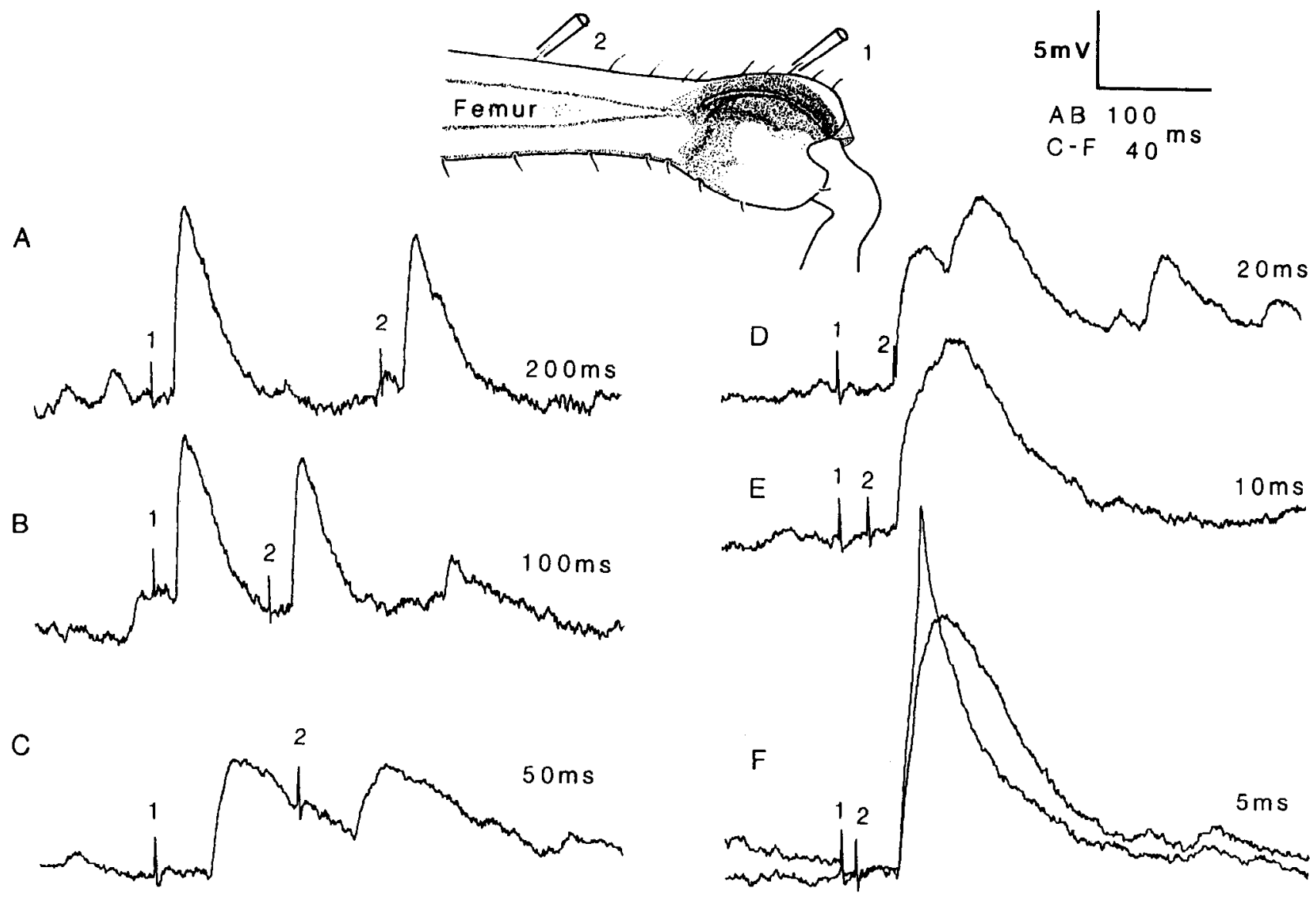

Figure 4. Summation of the EPSPs generated by two neighboring hairs in a spiking local interneuron. Two hairs on the dorsal distal femur (diagram) were stimulated sequentially with single electrical pulses at intervals of 200 to $5 \mathrm{msec} . A$, Hair 1 (the more distal one) generates a largeramplitude EPSP than hair 2. At an interval of $200 \mathrm{msec}$, the two EPSPs do not summate. $B-E$. Progressively reducing the interval between the spikes results in summation of their respective EPSPs. $F$, At an interval of $5 \mathrm{msec}$ the two EPSPs may evoke a spike in the interneuron. Two sweeps are superimposed, in only one of which is a spike evoked. The interneuron was held hyperpolarized by a small steady current 


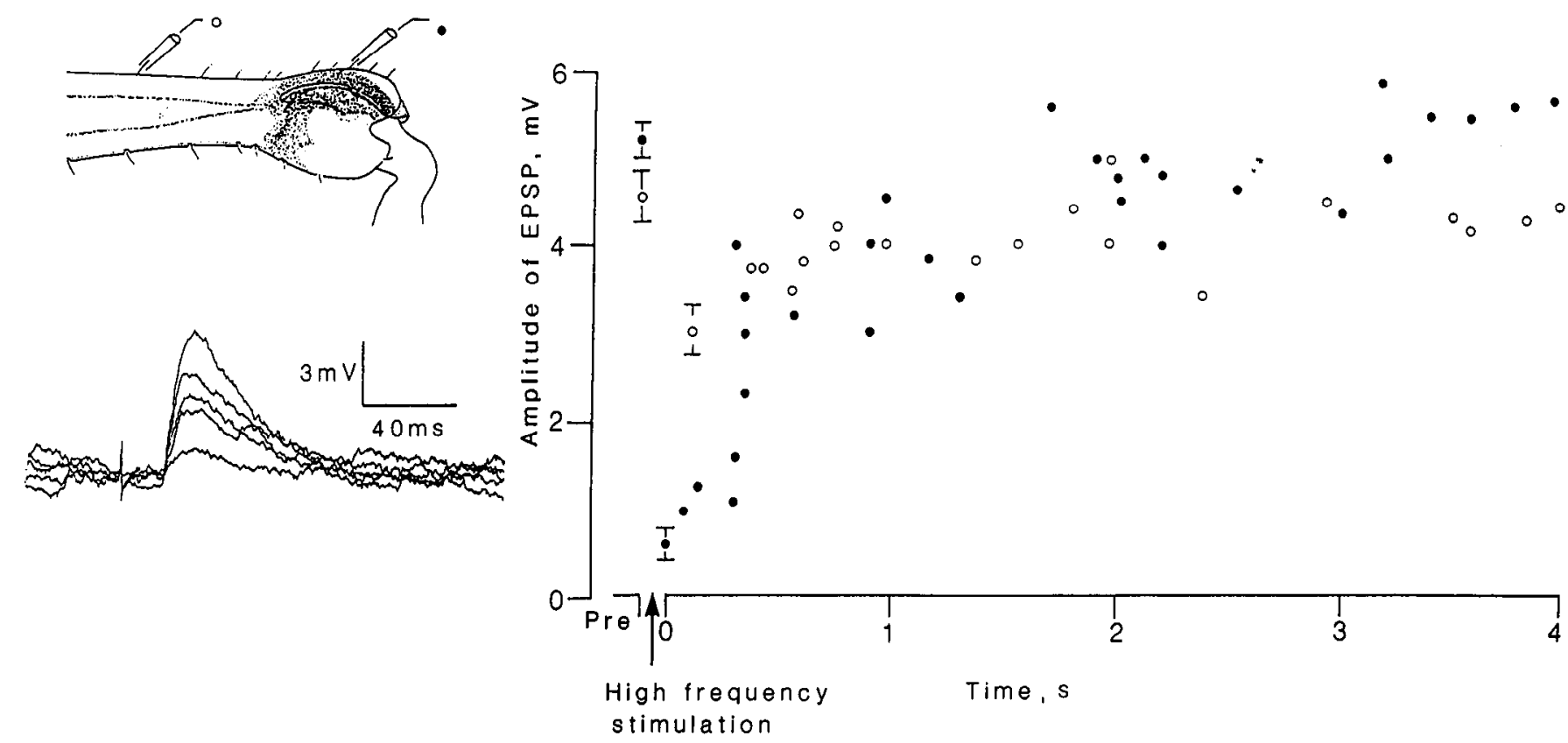

Figure 5. Recovery of EPSP amplitude after a period of high-frequency stimulation. Two hairs on the dorsal distal femur (diagram) were stimulated electrically with single shocks. The more distal hair (solid circles) was then stimulated at $30 \mathrm{~Hz}$ for 1.5 sec. The resulting recovery was then monitored by stimulating either hair with single shocks at selected intervals after the high-frequency stimulation. Selected EPSPs to illustrate the gradual recovery are shown at the bottom left, and the pooled data from many repetitions of this regime are plotted. The bars indicate the range of EPSP amplitudes observed before and just after the period of high-frequency stimulation.

which the hairs are activated but on the interval between their respective spikes. No instances were found of an input either reducing or facilitating a subsequent input.

To test whether interactions might occur when one afferent produces a high-frequency burst of spikes, the following paradigm was used (Fig. 5). Two hairs were stimulated separately with two shocks 1 sec apart, and then one of the hairs was stimulated at high frequency $(30 \mathrm{~Hz}, 1.5 \mathrm{sec})$. Each hair was then given a test shock at different intervals following the highfrequency stimulation. The amplitude of the EPSP from the hair that was stimulated at high frequency was subsequently depressed by $88 \%$, and the EPSP from the unstimulated hair was depressed by $23 \%$. Recovery of the EPSP from the unstimulated hair was complete within $1 \mathrm{sec}$, but the stimulated hair took some $3 \mathrm{sec}$. No potentiation of either EPSP could be seen after this period of stimulation. This experiment suggests that the heterosynaptic depression is either postsynaptic or due to presynaptic inhibition of the unstimulated afferent, but that the larger homosynaptic effect is presynaptic, presumably reflecting a decrease in the release of transmitter.

\section{Gain of the synaptic transmission}

Hairs within a receptive field differ in their effectiveness at evoking spikes in an interneuron when tested under comparable conditions. This difference appears to be correlated with the amplitude of the EPSPs that are recorded in the cell body of an interneuron, even though this is distant from the synaptic sites; larger EPSPs are more likely to evoke spikes. Extrapolations from these measurements to conclusions about effectiveness in evoking spikes cannot be drawn reliably as the recordings are not made at the spike initiating zone. The amplitude of the EPSP may simply reflect the different position of the synapses relative to the cell body. A direct but relative measure of the effectiveness of an input was made by eliciting 100 afferent spikes from a hair at frequencies that produce no decrement of their EPSPs, and recording the number that evoke a spike in an interneuron. If all afferent spikes lead to spikes in the interneuron, the synaptic connection has a gain of 1.0 , and if only half give spikes, the gain is 0.5 . This measure of gain refers only to the standard conditions in which the measurements are made and does not imply, for example, that a low-gain synaptic connection will always be ineffective at evoking spikes in an interneuron. It allows comparison of the effectiveness of the hairs within the fields of interneurons recorded in one locust, but can only give an indication of likely gains when comparisons are made between different locusts.

The following conclusions can be drawn. First, the gain of the synaptic connections from hairs can be as high as 1 , so that an individual afferent spike can evoke a spike in an interneuron. Second, the gain of a connection is never greater than 1 , so that several spikes are never seen in an interneuron in response to a single afferent spike. Third, the gain of the various afferent connections of hairs that contribute to the receptive field of an interneuron is not uniform. In a receptive field, only a few hairs, generally grouped together, have a gain of 1 . Close to these hairs are ones with a lower gain, but still capable to evoking spikes when their EPSPs sum. Farther away are hairs whose inputs alone are unable to make the interneuron spike, though they can be effective in combination with inputs from other hairs in the field, or inputs from other sources. These results therefore pose questions about the organization of a receptive field and the contribution that is made by the afferents from the constituent hairs.

\section{Construction of a receptive field}

The contribution of afferents from individual hairs to the receptive fields of interneurons is exemplified by the mapping of the femur onto four interneurons (Figs. 6-10). The pattern of 


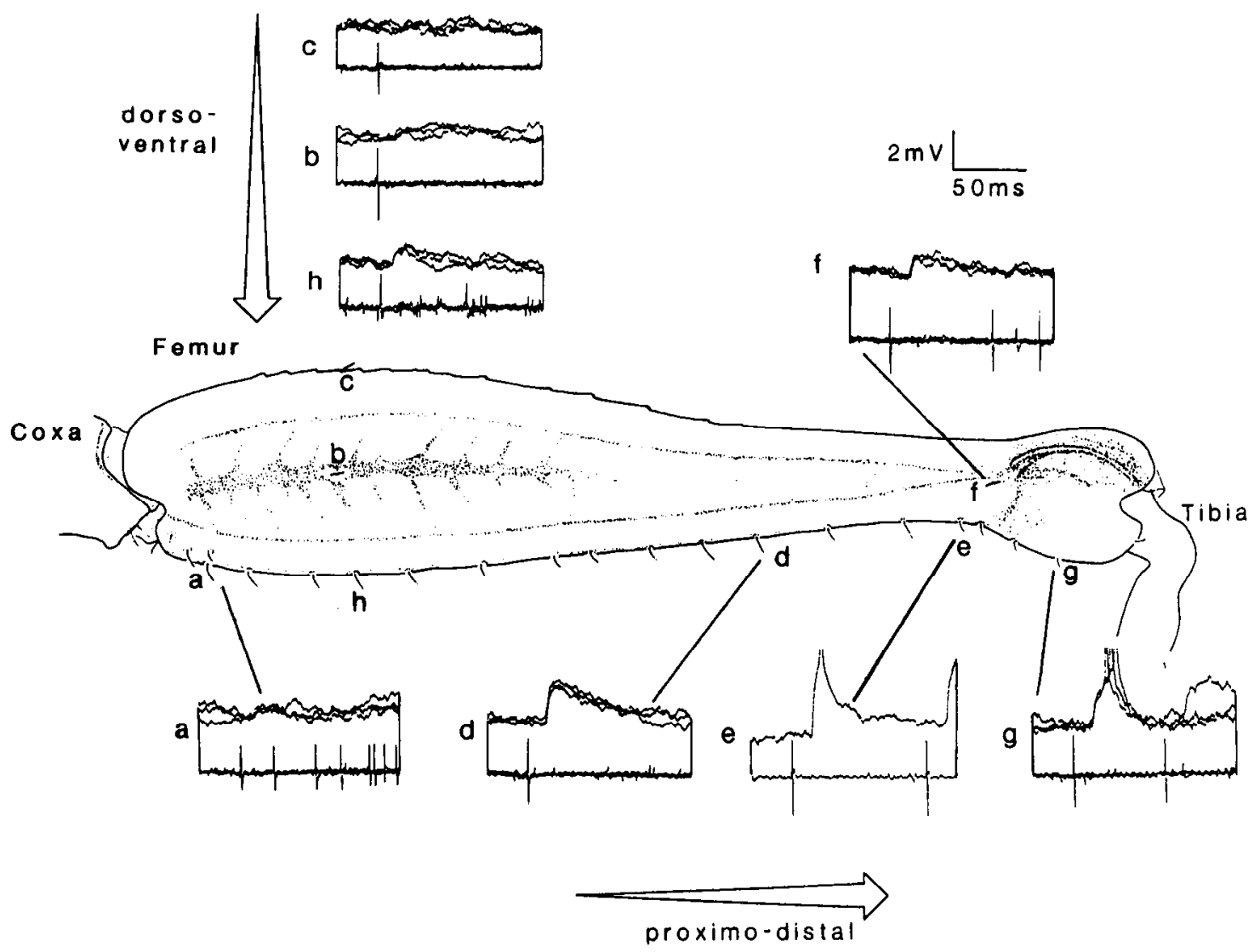

Figure 6. Hairs within the receptive field of an interneuron generate EPSPs of different amplitudes. This interneuron has a receptive field on the ventral femur and is held at its normal membrane potential. Fourteen hairs were sampled in one locust, of which eight are shown. The records show four superimposed sweeps triggered by the afferent spikes (lower traces), with the intracellularly recorded response of the interneuron on the upper trace. These conventions are used in subsequent figures. There are two gradients in the amplitude of the FPSPs, one increasing from proximal to distal (bottom row of records) and another increasing from dorsal to ventral (top column). Two distal ventral hairs ( $e, g$ ) make the interneuron spike. Hair $c$ on the dorsal surface does not connect. This interneuron has been recorded on 16 occasions and inputs from 99 hairs analyzed.

hairs is very similar in different animals. For example, in four animals, the number of large hairs on a dorsal row ranged only from 19 to 22 , and on a ventral row, from 15 to 19 . Most of the large hairs always occur in the same place, so their inputs to different interneurons can be compared in different animals.

The interneuron in Figure 6 is excited by hairs on the ventral femur and by some hairs on the anterior surface of the femur. These hairs generate EPSPs of different amplitudes and with different abilities to make the interneuron spike. There are gradients of increasing effectiveness along both the proximodistal and dorsoventral axes of the leg. The largest-amplitude EPSPs are generated by some of the most distal ventral hairs, and these often lead to spikes in the interneuron (hairs $e, g$, in Fig. 6). Hairs progressively more proximal on the ventral surface generate progressively smaller-amplitude EPSPs, so that the most proximal hair (hair $a$ in Fig. 6) generates an EPSP that is less than $30 \%$ of the amplitude of the most distal hair (hair $g$ in Fig. 6). The proximodistal boundary of the receptive field ends abruptly at the joints of the leg so that no hairs on either the coxa or the tibia make connections. The gradient in the amplitude of the EPSPs is steeper in the dorsoventral axis. For example, hair $f$ on the anterior surface behind the semi-lunar process, and less than $500 \mu \mathrm{m}$ from hair $e$ on the ventral surface, generates an EPSP that is only half as large. Similarly, hair $b$ on the middle of the anterior face generates a smaller EPSP than hair $h$ at the same proximodistal level on the ventral surface, while hair $c$ on the dorsal surface makes no connection, in common with all other dorsal hairs (Fig. 6).

The interneuron in Figure 7 also has a receptive field on the ventral femur, but its most powerful inputs are from proximal hairs (e.g., hair a). Along the proximodistal axis of the femur, the more distal the hair, the smaller the amplitude of its EPSP, so that the gradicnt in the amplitude of the EPSPs increases from distal to proximal, the reverse of the interneuron in Figure 6 . The most distal hair $g$ apparently makes no connection with this interneuron. Despite the difference in the amplitudes of the EPSPS generated by the different hairs, their rise times are all similar. This may indicate that there is no difference in the electrotonic distance from the synapses of the different afferents to the recording site. Moreover, it suggests that the differing amplitudes are not simply the result of the spatial distribution of the synapses from the different hairs. The same hairs contribute to the receptive fields of this interneuron and the one in Figure 6. For example, hair $a$ at the proximal end of the femur makes a low-gain connection with the interneuron of Figure 6 , but a high-gain connection with the interneuron of Figure 7. The converse is true for hairs $e$ and $g$ at the distal end. The overlap of the gradients means that hairs midway along the 


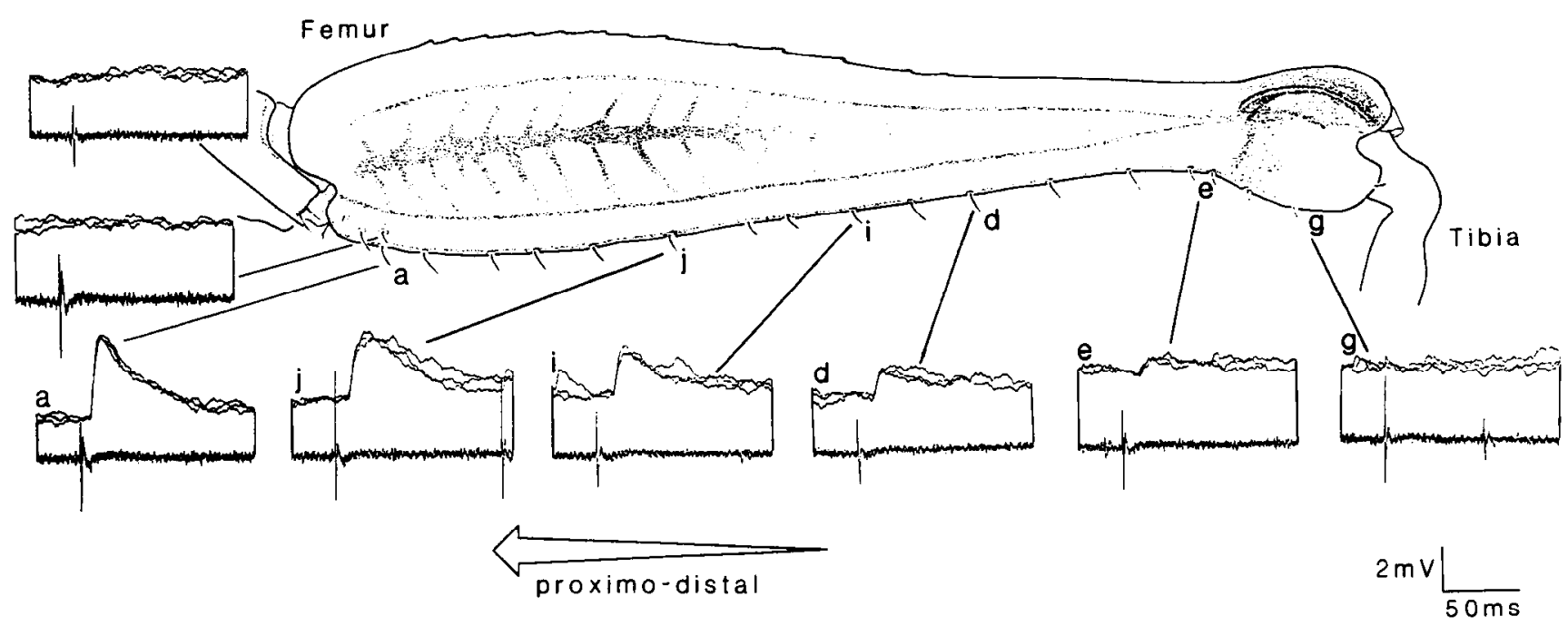

Figure 7. An interneuron with a receptive field on the ventral tibia. The gradient of EPSP amplitudes increases from distal to proximal. Twenty hairs were sampled in one locust, of which eight are shown. Only hairs on the ventral surface of the femur connect with this interneuron; hairs on the ventral rim of the coxa or on the anterior face of the femur do not connect. The interneuron was held hyperpolarized by a steady $0.5 \mathrm{nA}$ current. This interneuron was recorded on four occasions, and inputs from 42 hairs were analyzed.

ventral surface, such as hair $d$ can contribute approximately equally to both interneurons.

The interneuron in Figure 8 has its receptive field on the anterior and ventral surfaces of the femur. The hairs generating the largest-amplitude EPSPs are on the anterior surface just proximal and ventral to the semi-lunar process. The gradient of effectiveness declines proximally and dorsally. For example, along the proximodistal axis hair $b$ produces an EPSP that is only half the amplitude of that of the most distal hair on the anterior surface (Fig. 8). In the dorsoventral axis, hair $o 200 \mu \mathrm{m}$ dorsal to $b$ on the anterior surface makes no connection, nor does hair $c 200 \mu \mathrm{m}$ farther away on the dorsal surface (Fig. 8). The steep gradient in the dorsoventral axis is illustrated further by hair $f$ and its three neighbors, spaced $500 \mu \mathrm{m}$ apart (box in Fig. 8). Hair $f$, the most dorsal of the four, produces a $0.5 \mathrm{mV}$ EPSP that is only a quarter of the amplitude of that produced by hair $/$ ventral to it, which has the highest gain in this receptive field. Hair $n$ apparently does not connect, while hair $m$ ventral to it produces a $1 \mathrm{mV}$ EPSP.

Some of the same hairs that are part of the receptive field of

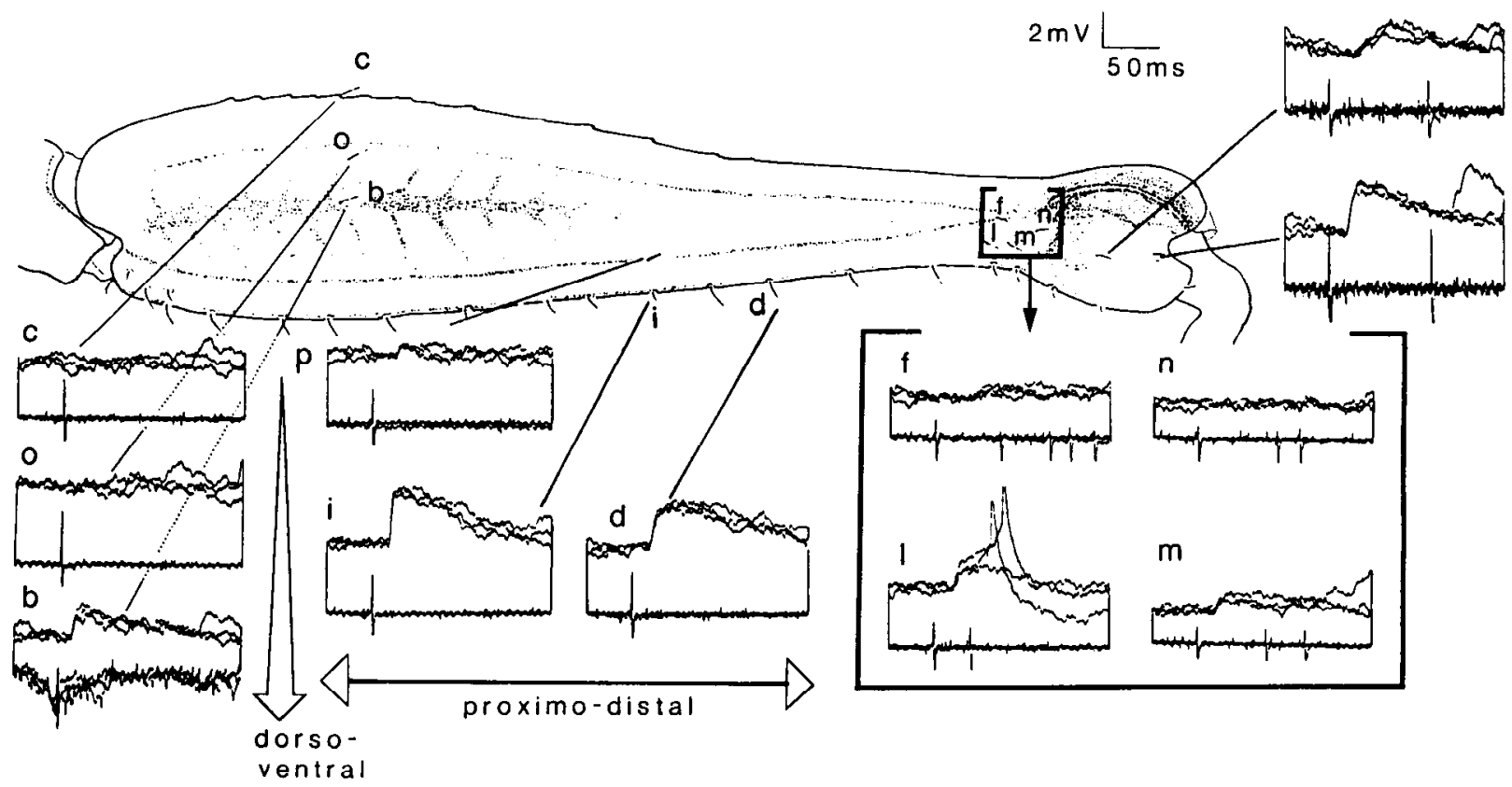

Figure 8. An interneuron with a receptive field on the anterior and ventral faces of the femur. Fifteen hairs were sampled in one locust, of which 12 are shown. The hairs generating the largest-amplitude EPSPs are on the anterior surface proximal to the semi-lunar process. Hairs on the dorsal surface do not connect. This interneuron was recorded on three occasions, and inputs from 31 hairs were analyzed. 


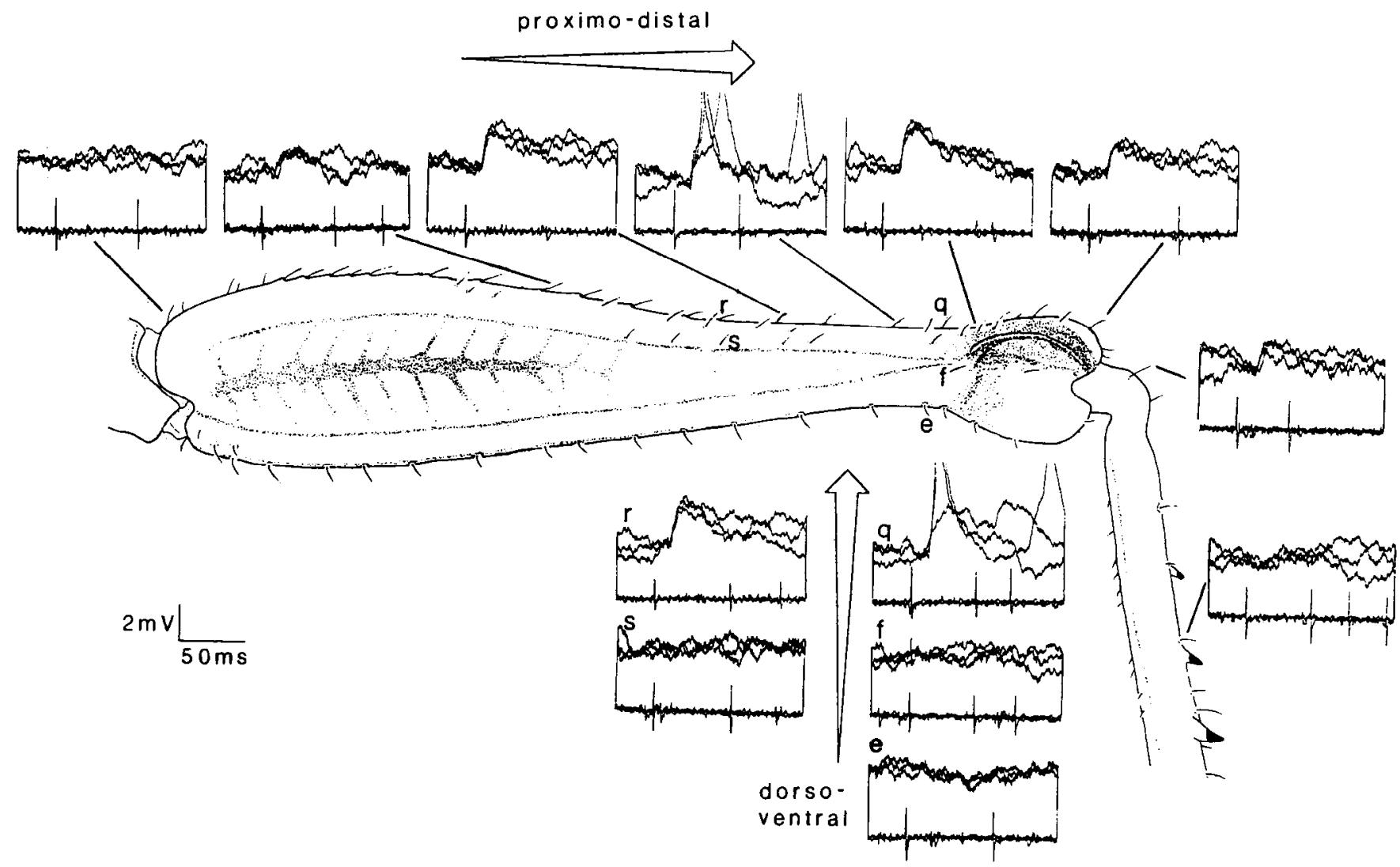

Figure 9. An interneuron with a receptive field on the dorsal surface of the femur and on the proximal dorsal part of the tibia. Thirty-nine hairs were sampled in one locust, of which 13 are shown. The hairs generating the largest-amplitude EPSPs are on the distal part of the femur. The effectiveness of the hairs declines proximally on the femur and distally on the tibia. The interneuron was held at its normal membrane potential. This interneuron was recorded on 12 occasions, and inputs from 102 hairs were analyzed.

the interneuron in Figure 8 also contribute to the receptive fields of the interneurons in Figures 6 and 7. For example, hair $b$ produces a small EPSP in the interneuron in Figure 6 and a larger one in Figure 8, while hair $f$ has the converse effect. Hair $d$ has a similar effect on the interneurons in Figures 6-8, as does hair $i$ on the interncurons in Figures 7 and 8 . These are all measures relative to the EPSPs produced in the respective interneurons by other afferents.

The interneuron in Figure 9 has a receptive field on the dorsal surface of the femur and on the proximal, dorsal surface of the tibia. Again, there are two gradients of effectiveness within the field: proximodistal and dorsoventral. The most effective hairs (largest-amplitude EPSPs and highest gains) are on the dorsal femur, $1 \mathrm{~mm}$ from the distal end. The effectiveness of the hairs gradually declines proximally so that the most proximal hair on the dorsal femur apparently makes no connection. The effectiveness also declines distally, so that hairs closer to the femorotibial joint are less effective. For example, the most distal hair generates an EPSP that is only $30 \%$ of the amplitude of hairs $1.5 \mathrm{~mm}$ more proximal. The decline in effectiveness also continues with the hairs on the tibia. Hairs as far distal as the first tibial spine connect with the interneuron, but more distal ones do not.

The decline in the effectiveness of the EPSPs is steeper in the dorsoventral axis. For example, at the same proximodistal level hair $f$ (Fig. 9) apparently makes no connection, although it is only $900 \mu \mathrm{m}$ ventral to one of the most effective hairs $(q)$, and hair $e$ on the ventral surface makes no connection. A similar sharp decline also occurs with more proximal hairs. Hair $r$ on the dorsal surface generates a $3 \mathrm{mV}$ EPSP, but hair $s 350 \mu \mathrm{m}$ away on a more ventral row apparently makes no connection (Fig. 9). None of the hairs that are part of the receptive fields of the three preceding interneurons (Figs. 6-8) connect with this interneuron. The mapping of the femur onto the four interneurons and the gradients of EPSP amplitudes are summarized in Figure 10.

\section{Density and type of receptor}

The hairs on the femur are relatively uniformly spaced, and all appear to be of the same low-velocity threshold type (Newland, 1991a). On the tibia, however, the density is not uniform and hairs of two physiological types occur. Do these two factors also contribute to regional differences in the receptive field of an interneuron? To answer this question, an interneuron was chosen that has its receptive field on the dorsal tibia (the one bearing two rows of spines) and dorsal tarsus. Brushing the tibia and tarsus with a fine paintbrush shows qualitative differences in this receptive field (Fig. 11). Touching near the femorotibial joint produces a depolarization but only an occasional spike. More distal stimuli produce progressively more powerful responses with more spikes and at higher frequencies. The density of hairs follows a similar gradient: there are few hairs proximal to the first spine but many close to the tibiotarsal joint. Associated with each of the spines, and on the proximal tibia, are 

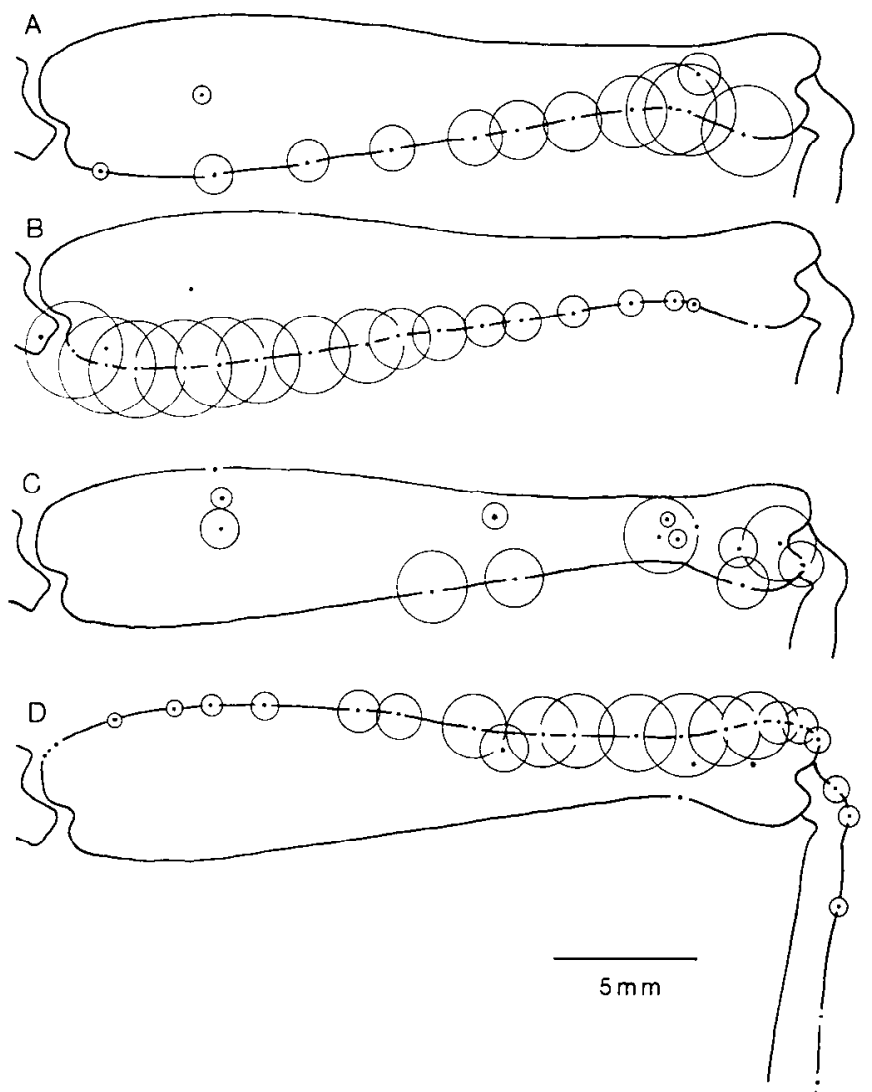

Figure 10. Gradients in the amplitudes of EPSPs in the receptive fields of four spiking local interneurons that map the surface of the femur. The amplitude of the EPSPs generated by the hairs (dots) is proportional to the diameter of the circles. The hairs that do no connect are represented only by dots. $A-D$ represent the interneurons shown in Figures $6-9$, respectively.

high-threshold hairs that respond phasically to a deflection (Newland, 1991a). To test the effectiveness of these hairs relative to adjacent low-threshold hairs, comparisons were made between the hairs in an anterior, dorsal row between spines 3 and 6 (Fig. 12). There are three hairs in this row between each spine. The distal high-threshold hair connects with the interneuron, but the two low-threshold hairs have no detectable effect (Fig. $12 A-C)$. Nevertheless, low-threshold hairs in adjacent rows do connect with the interneuron (Fig. 13). There is also a gradient of effectiveness to the inputs provided by both the high- and low-threshold hairs, with its center at the middle of the tibia (Fig. 13). The high-threshold hairs generating the largest-amplitude EPSPs and with the highest gains occur between spines 1 and 6 (Fig. 13). Hairs proximal to spine 1 generate smalleramplitude EPSPs, as do hairs that are distal to spine 6 (Fig. 13). The effectiveness of a stimulus within the receptive field of this interneuron therefore depends on a combination of the density of the receptors, their type, and the gain of the synaptic connection that their afferents make with the interneuron.

\section{Discussion}

Properties of the synaptic connection

The hair afferents on a hind leg make direct excitatory connections with particular spiking local interneurons in a midline population. The first EPSP evoked by a sequence of afferent spikes is always the largest, and subsequent ones decrement if

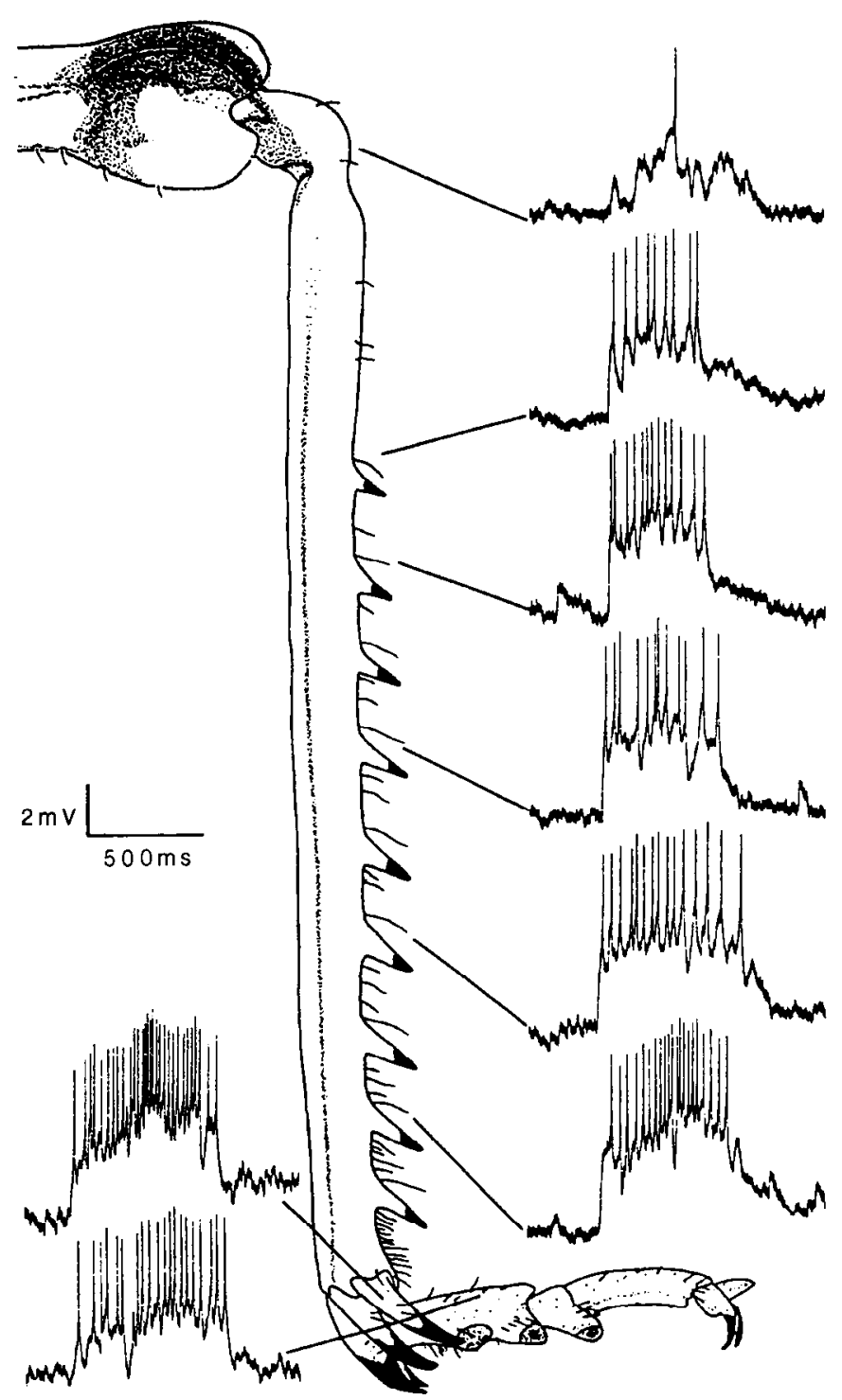

Figure 11. Qualitative differences in the effectiveness of inputs from different parts of the receptive field of an interneuron on the dorsal tibia and dorsal tarsus. Touching several hairs simultaneously with a small paintbrush reveals a gradient of effectiveness increasing proximally (near the femur) to distally (on the tarsus). The drawing in this and subscquent figures shows only the anterior and not the posterior row of spines.

they occur at intervals of less than $2 \mathrm{sec}$. The synaptic connection saturates in response to the high frequency of spikes that are generated by a natural movement of a hair. The amplitude of depolarization produced by a single afferent spike is similar to that produced by a high-frequency burst of spikes. The reason for the hairs signaling a deflection with a burst of spikes must therefore reside in the duration and not the amplitude of the depolarization that they produce in the interneurons. The synaptic connection therefore seems to be designed to ensure that small signals reach the next stage of processing. This feature is also in keeping with the high gain of the synaptic connections from particular hairs within a receptive field (see below).

No indication of facilitation or activity-dependent potentiation has been found at any of these synaptic connections. They therefore contrast with the connections that hair afferents from the proleg of the caterpillar of the moth Manduca make with 


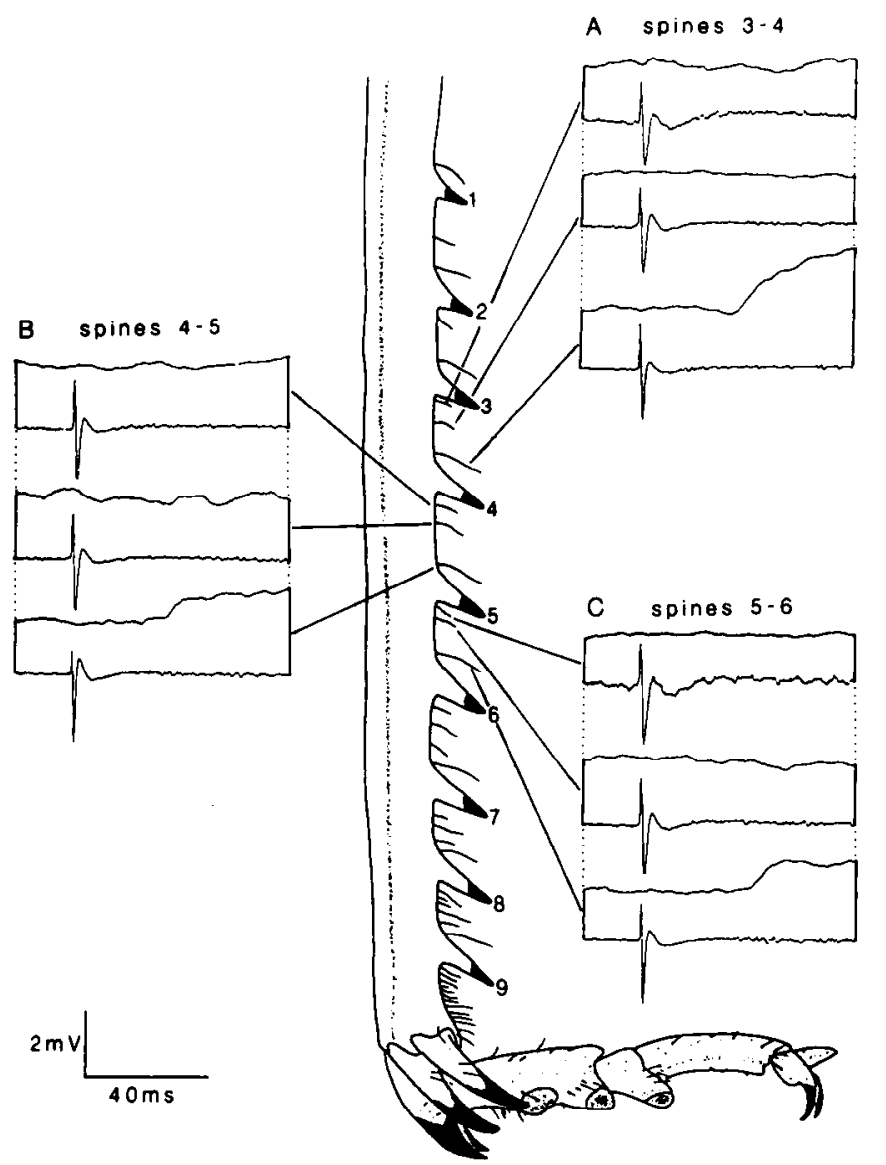

Figure 12. Hairs with different physiological response properties make different connections with an interneuron. This interneuron has the same receptive field as the one in Figure 11 . Between each of the spines in an anterior row is a repeating pattern of hairs with a long, highthreshold hair at the proximal base of a spine, and two or more shorter low-threshold hairs. The long hair at the base of each of spines $4(A)$, $5(B)$, and $6(C)$ connects with the interneuron, but no effect of the shorter hairs between these spines can be detected. Each of the records is an average of 50 sweeps triggered by the afferent spikes.

motor neurons (Trimmer and Weeks, 1991). Here, the synaptic potentials facilitate and show long-term potentiation, depending on the pattern of preceding activity.

Afferents from adjacent hairs on a locust hind leg project to the same region of neuropil, so that the surface is mapped in an ordered fashion onto the ventral neuropil of the metathoracic ganglion (Newland, 1991b). This mapping is similar in principle to that for hairs on the body of other insects (Murphey et al., 1980, 1989a; Peterson and Weeks, 1988). For example, hairs on the proximal femur project more anteriorly in the ganglion than do distal ones, anterior hairs project more medially than do posterior ones, and dorsal hairs project more dorsally than do ventral ones. This precise arrangement suggests that the synapses from two adjacent hairs on the same axis of the leg should be close together on the ventral field of a spiking local interneuron (Watson and Burrows, 1985). The physiological interactions between such synapses are, however, limited. Two inputs do sum with each other, and a high-frequency signal in one can temporarily reduce the effectiveness of an input from the second. No heterosynaptic facilitation was found, however, a characteristic also shared by hair afferent to motor neuron synapses in Manduca (Trimmer and Weeks, 1991).

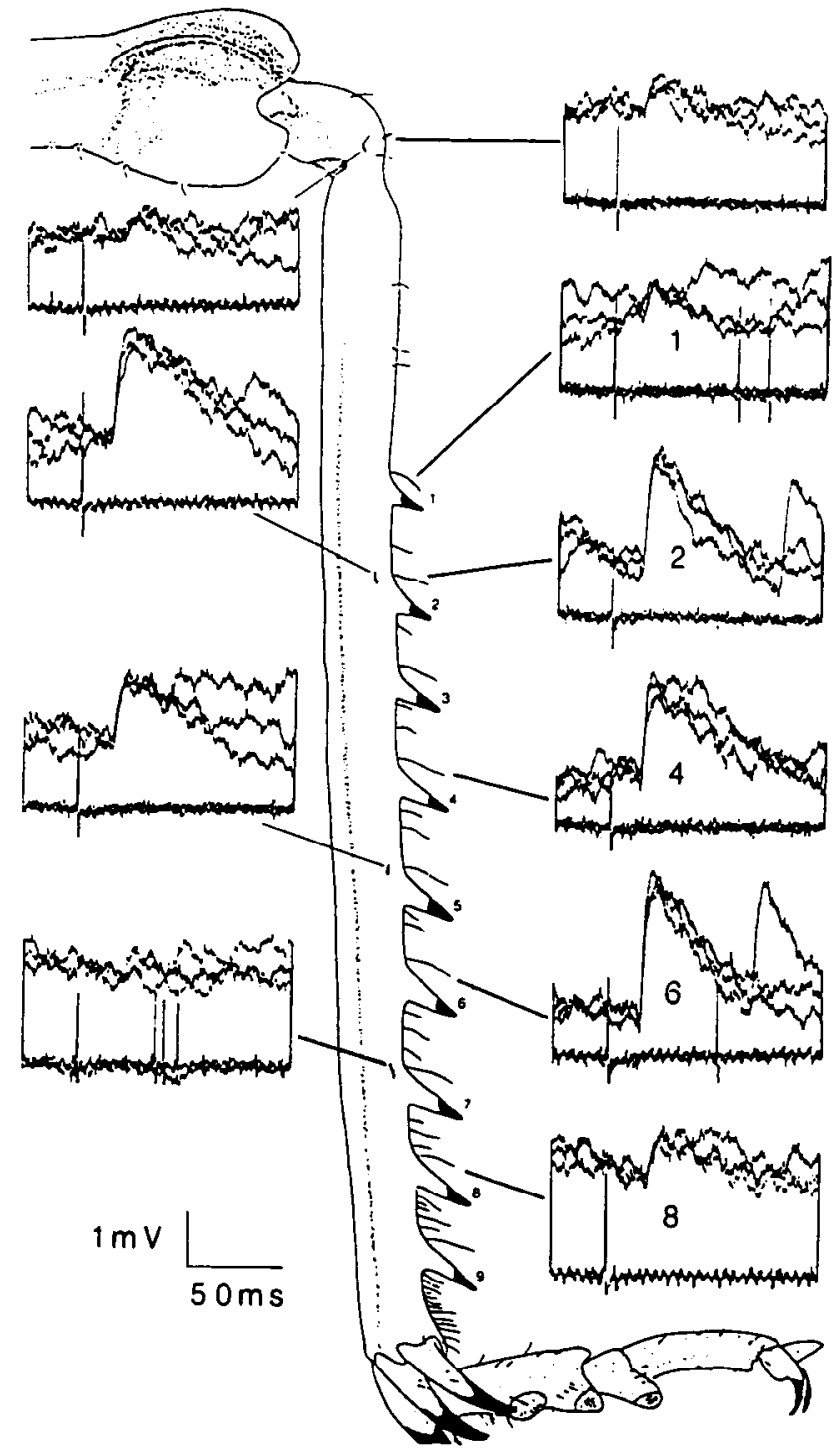

Figure 13. Proximodistal gradient in the amplitudes of EPSPs generated by tibial hair afferents in the interneuron also shown in Figures 11 and 12 . The left column shows the EPSPs generated by low-threshold hairs on the anterior face, and the right column, the EPSPs generated by high-threshold hairs at the bases of the spines. Fourteen hairs were sampled, of which 10 are shown. The spines are numbered on the diagram. This interneuron was recorded on 11 occasions, and inputs from 78 hairs were analyzed.

\section{Synaptic gain}

The synaptic gain can be high so that the reliability of information transmission through these local interneurons can be high. Two measures of the effectiveness of a synaptic input have been used: EPSP amplitude, and the ability of single afferent spikes to evoke spikes in an interneuron. There is a strong correlation between these two measures in that the largest EPSPs are most likely to evoke spikes. All recordings have been made from the soma, which is separated from the input synapses by a thin process some $200 \mu \mathrm{m}$ long. This process could act as a low-pass filter, which may explain the similar rise times of all amplitudes of EPSPs. Alternatively, the similarity in rise times may indicate that the different synapses are all at a similar electrotonic distance from the recording site and that their dif- 
ferent amplitudes result more from presynaptic factors, such as the number of release sites or the number of quanta released.

Processing of exteroceptive signals in the locust parallels closely the way that mammals process sensory signals from hair follicle receptors. In the cat, for example, spinocervical tract interneurons transmit single afferent spikes with a reliability that can approach 90\% (Brown et al., 1987a). The reliability in this pathway is, however, enhanced by amplification that results in more than one interneuron spike for each afferent spike. The input to these neurons involves both mono- and polysynaptic pathways, and the spikes arise only from the polysynaptic component (Brown et al., 1987b). It seems, therefore, that this stage in mechanosensory integration is concerned with responding to all the signals that are provided by the high-gain hairs.

The processing of exteroceptive hair inputs in both the cat and locust contrasts with the processing of proprioceptive signals. In the cat, inputs from many primary afferents from muscle spindles are needed before the monosynaptic connection evokes spikes in motor neurons (Burke and Rudomin, 1977). Similarly in the locust, afferents from a chordotonal organ that monitors the movement and position of the femorotibial joint make lowgain synapses with motor neurons (Burrows, 1987a). Summation of spikes from one or many afferents is needed to evoke motor spikes. This suggests that it is important for the animal to assess carefully the significance of any signal provided by the proprioceptors before it is either acted upon or discarded.

\section{Organization of receptive fields}

Data from all the local interneurons allow the following generalizations to be drawn about the processing of exteroceptive signals and the organization of receptive fields.

1. Afferents from most hairs within the boundary of a receptive field of an interneuron make synaptic connections. No discontinuities in the excitatory areas of a field have been found, and no fields contain separate excitatory patches on different parts of leg. Inhibitory and excitatory regions can, however, be discontinuous (Burrows and Siegler, 1985). Only rarely do some hairs within a field apparently not connect with an interneuron. This contrasts with the organization of the receptive fields of interneurons in the crayfish that receive inputs from mechanosensory afferents on the abdomen. Here, the afferents within a receptive field appear to connect in a probabilistic fashion (Calabrese, 1976), although this may be related to their directional response properties and the need to preserve the coding of direction (Wiese et al., 1976).

2. Not all the receptors of the same physiological type have the same effect on an interneuron. The amplitudes of EPSPs that are generated by the hairs within the same field can vary by a factor of 5 and the gains of their synaptic connections can also vary.

3. Hairs in one region of a receptive field have the greatest potency. This region can often be toward one edge, or in the center of the field, as in spinocervical tract neurons in the cat (Brown et al., 1986). Thus, for example, the most effective part of the fields of the interneurons in Figures 6-8 is toward one end, but for the interneuron in Figure 13 it is at the center.

4. Steep gradients can exist in the effectiveness of hairs within a field. Hairs at the edge of a field separated by no more than $500 \mu \mathrm{m}$ can generate EPSPs that differ by a factor of 2 in their amplitude and gain. Typically a field will contain two gradients of effectiveness that are aligned with particular axes of the leg (e.g., dorsoventral or proximodistal). The boundaries of the fields are often abrupt, particularly at the joints.
5. The only correlation between effectiveness of an input and the receptors of one type is their position within the receptive field. There is, for example, no correlation with the length of the hair shaft. For a locust projection interneuron (A4I1) sensitive to wind on the neck, there is, however, a correlation between the effectiveness of the input and the length of the hair and therefore its sensitivity to wind stimuli (Pflüger and Burrows, 1990). A similar correlation is also found for some cricket cercal hairs (Shepherd et al., 1988).

6. Receptors of different physiological types may differ in their conncctions; some connect, and others do not. This study has been restricted to the different types of hairs (trichoid sensilla) and has deliberately ignored the contribution of another class of exteroceptor, the basiconic sensilla. These have shorter shafts and are innervated by several sensory neurons (Zacharuk, 1985). Most of these sensory neurons carry chemoreceptive information, but at least one neuron for each sensillum carries mechanoreceptive information. A subsequent report will explore whether the interneurons examined here process the mechanoreceptive information from these basiconic afferents. In flies, the chemo- and mechanosensory afferents end in different regions of neuropil, suggesting that they contact different populations of interneurons (Murphey et al., 1989b).

7. The same hair contributes to the receptive field of more than one interneuron. In one interneuron the connection may reliably evoke a spike, but in another may require summation with other inputs before a spike can be generated. The position of a hair on the leg will therefore be represented in the local circuits by the activity of several interneurons. For example, a stimulus to the dorsal surface of the tibia that leads to a reflex depression of the trochanter, flexion of the tibia, and levation of the tarsus (Siegler and Burrows, 1986) will activate the highgain synaptic connections to the interneuron in Figure 13 and the low-gain ones to the interneuron in Figure 9. Similarly, a stimulus to the distal end of the ventral femur will activate the high-gain synaptic connections to the interneuron in Figure 6 and the low-gain ones to the interneuron in Figure 7.

\section{Functional implications for this type of organization}

The physiological results presented here indicate great specificity in the connections made between hair afferents and midline spiking local interneurons. This means that these interneurons provide a precise mapping of the surface of the hind leg and preserve the spatial information provided by the receptors. An afferent neuron may also connect with other elements of the local circuit, such as other spiking local interneurons (Nagayama and Burrows, 1990), nonspiking interneurons (Laurent and Burrows, 1988), projection interneurons (Laurent, 1988; Laurent and Burrows, 1988), and more rarely some motor neurons (Laurent and Hustert, 1988). The sensory signals giving information about a stimulus to a particular region of a hind leg are thus distributed to a set of interneurons that comprises only a small fraction of the total complement in the circuit. This contrasts with the processing of mechanosensory signals in the leech, where the small number of sensory neurons connect with most of the interneurons that mediate the local bending reflexes (Lockery et al., 1989; Lockery and Kristan, 1990). The localization of a stimulus does not therefore reside in particular interneurons, but emerges as a distributed property of the whole network.

In insects the accuracy and specificity of coding of the spatial arrangement is nevertheless high, as is shown by the behavior. For example, the functioning of the gin traps on the abdomen 
of privet hawk moth caterpillars depends on a discrimination between the activation of receptors on the inside and margins of the trap as opposed to those on the outside (Bate, 1973). Grooming movements of the legs are accurately directed to the receptors that are stimulated (Zack, 1978; Honegger et al., 1979), and stimulation of receptors on different surfaces of the legs leads to distinct local reflex movements (Siegler and Burrows, 1986).

Anatomically, this precision is represented in a spatial map that the afferents form in the neuropil (Anderson, 1985; Murphey et al., 1989d; Newland, 1991b) and in the characteristic projection patterns of the ventral branches of individual interneurons. Input synapses are made onto the ventral branches (Watson and Burrows, 1985) so that the region of neuropil to which these branches project may reflect the receptive field. Previous attempts to match the shapes of the interneurons to the fields were inconclusive (Burrows and Siegler, 1984), but now that the fields have been defined more precisely and a somatotopic map of the afferents is known (Newland, 1991b), a recxamination of this correlation might well be informative.

\section{References}

Anderson $H$ (1985) The distribution of mechanosensory hair afferents within the locust central nervous system. Brain Res 333:97-102.

Bacon JP, Altman JS (1977) A silver intensification method for cobaltfilled neurones in wholemount preparations. Brain Res 138:359-363.

Bate CM (1973) The mechanism of the pupal gin trap. I. Segmental gradients and the connexions of the triggering sensilla. J Exp Biol 59: 95-107.

Brogan RT, Pitman RM (1981) Axonal regeneration in an identified insect motoneurone. J Physiol (Lond) 319:34P-35P.

Brown AG, Noble R, Rowe MJ (1986) Receptive field profiles and integrative properties of spinocervical tract cells in the cat. J Physiol (Lond) 374:335-348.

Brown AG, Koerber HR, Noble R (1987a) Excitatory actions of single impulses in single hair follicle afferent fibres on spinocervical tract neurones in the cat. J Physiol (Lond) 382:291-312.

Brown AG, Koerber HR, Noble R (1987b) An intracellular study of spinocervical tract cell responses to natural stimuli and single hair afferent fibres in cats. J Physiol (Lond) 382:331-354.

Burke RE, Rudomin P (1977) Spinal neurons and synapses. In: Handbook of physiology, Sec 1, Vol 1, The nervous system: the cellular biology of neurons (Kandel ER, ed), pp 877-944. Washington, DC: American Physiological Society.

Burrows M (1987a) Parallel processing of proprioceptive signals by spiking local interneurones and motor neurones in the locust. J Neurosci 7:1064-1080.

Burrows $M(1987 \mathrm{~b})$ Inhibitory interactions between spiking and nonspiking local interneurones in the locust. J Neurosci 7:3282-3292.

Burrows M, Laurent G (1989) Reflex circuits and the control of movement. In: The computing neuron (Durbin R, Miall C, Mitchison G, eds), pp 224-261. Wokingham, UK: Addison Wesley.

Burrows M, Pflüger HJ (1986) Processing by local interncurons of mechanosensory signals involved in a leg reflex of the locust. J Neurosci 6:2764-2777.

Burrows M, Siegler MVS (1982) Spiking local interneurons mediate local reflexes. Science 217:650-652.

Burrows M, Siegler MVS (1984) The morphological diversity and receptive fields of spiking local interneurones in the locust metathoracic ganglion. J Comp Neurol 224:483-508.

Burrows M, Siegler MVS (1985) The organization of receptive fields of spiking local interneurones in the locust with inputs from hair afferents. J Neurophysiol 53:1147-1157.

Calabrese RL (1976) Crayfish mechanoreceptive interneurons: I. The nature of ipsilateral excitatory inputs. J Comp Physiol 105:83-102.

Hodgson ES, Lettvin JY, Roeder KD (1955) Physiology of a primary chemoreceptor unit. Science 122:417-418.

Honegger HW, Reif H, Muller W (1979) Sensory mechanisms of eye cleaning behavior in the cricket Gryllus campestris. J Comp Physiol 129:247-256.
Laurent $G$ (1987) The role of spiking local interneurons in shaping the receptive fields of intersegmental interneurons in the locust. $J$ Neurosci 7:2977-2989.

Laurent G (1988) Local circuits underlying excitation and inhibition of intersegmental interneurones in the locust. J Comp Physiol 162: 145-157.

Laurent G, Burrows M (1988) A population of ascending intersegmental interneurones in the locust with mechanosensory inputs from a hind leg. J Comp Neurol 275:1-12.

Laurent GJ, Hustert R (1988) Motor neuronal receptive fields delimit patterns of activity during locomotion of the locust. J Neurosci 8: 4349-4366.

Lockery SA, Wittenberg G, Kristan WB Jr, Cottrell GW (1989) Function of identified interneurons in the leech elucidated using neural networks trained by back-propagation. Nature 340:468-471.

Lockcry SR, Kristan WB Jr (1990) Distributed processing of sensory information in the leech. I. Input output relations of local bending reflex. J Neurosci 10:1811-1815.

Murphey RK, Jacklet A, Schuster L (1980) A topographic map of sensory cell terminal arborizations in the cricket CNS: correlation with birthday and position in a sensory array. J Comp Neurol 191: 53-64.

Murphey RK, Possidente DR, Vandervorst P, Ghysen A (1989a) Compartments and the topography of leg afferent projections in Drosophila. J Neurosci 9:3209-3217.

Murphey RK, Possidente D, Pollack G, Merritt DJ (1989b) Modalityspecific axonal projections in the CNS of the flies Phormia and Drosophila. J Comp Neurol 290:185-200.

Nagayama T (1990) The organisation of receptive fields of an anteromedial group of spiking local intcrncurones in the locust with exteroceptive inputs from the legs. J Comp Physiol 166:471-476.

Nagayama T, Burrows M (1990) Input and output connections of an anteromedial group of spiking local interneurones in the metathoracic ganglion of the locust. J Neurosci 10:785-794.

Newland PL (1991a) Physiological properties of afferents from tactile hairs on the hindlegs of the locust. J Exp Biol 155:487-503.

Newland PL (1991b) Morphology and somatotopic organisation of the central projections of afferents from tactile hairs on the hind leg of the locust. J Comp Neurol 312:493-508.

Peterson BA, Weeks JC (1988) Somatotopic mapping of sensory neurons innervating mechanosensory hairs on the larval prolegs of $\mathrm{Man}$ duca sexta. J Comp Neurol 275:128-144.

Pflüger HJ, Burrows M (1990) Synaptic connections of different strength between wind-sensitive hairs and an identified projection interneuron in the locust. Eur J Neurosci 2:1040-1050.

Shepherd D, Kamper G, Murphey RK (1988) The synaptic origins of receptive field properties in the cricket cercal sensory system. J Comp Physiol 162:1-11.

Siegler MVS, Burrows M (1983) Spiking local interneurons as primary integrators of mechanosensory information in the locust. J Neurophysiol 50:1281-1295.

Siegler MVS, Burrows M (1984) The morphology of two groups of local spiking interneurons in the metathoracic ganglion of the locust. J Comp Neurol 224:463-482.

Siegler MVS, Burrows M (1986) Receptive fields of motor neurones underlying local tactile reflexes in the locust. J Neurosci 6:507-513.

Trimmer BA, Weeks JC (1991) Activity-dependent induction of facilitation, depression, and post-tetanic potentiation at an insect central synapse. J Comp Physiol 168:27-43.

Watson AHD, Burrows M (1985) The distribution of synapses on the two fields of neurites of spiking local interneurones in the locust. J Comp Neurol 240:219-232.

Weeks JC, Jacobs GA (1987) A reflex behavior mediated by monosynaptic connections between hair afferents and motoneurons in the larval tobacco hornworm. J Comp Physiol 160:315-329.

Wiese K, Calabrese RL, Kennedy D (1976) Integration of directional mechanosensory input by crayfish interneurons. J Neurophysiol 39: 834-843.

Zacharuk RY (1985) Antennae and sensilla. In: Comprehensive insect physiology, biochemistry and pharmacology, Vol 6 (Kerkut GA, Gilbert LI, eds), pp 1-69. Oxford, UK: Pergamon.

Zack S (1978) Head grooming behaviour in the praying mantis. Anim Behav 26:1107-1119. 